\title{
Essentials of Low-Power Electrocution: Established and Speculated Mechanisms
}

\author{
Mark W. Kroll, PhD, FIEEE; Raymond M. Fish. PhD, MD; Dhanunjaya Lakkireddy, MD; \\ Richard M. Luceri, MD; Dorin Panescu, PhD, FIEEE
}

\begin{abstract}
Even though electrocution has been recognized and studied - for over a century, there remain several common misconceptions among medical professional as well as lay persons. This review focuses on "low-power" electrocutions rather than on the "high-power" electrocutions such as from lightning and power lines. Low-power electrocution induces ventricular fibrillation (VF). We review the 3 established mechanisms for electrocution: (1) shock on cardiac Twave, (2) direct induction of $\mathrm{VF}$, and (3) long-term high-rate cardiac capture reducing the VF threshold until VF is induced. There are several electrocution myths addressed, including the concept - often taught in medical school that direct current causes asystole instead of VF and that electrical exposure can lead to a delayed cardiac arrest by inducing a subclinical ventricular tachycardia (VT). Other misunderstandings are also discussed.
\end{abstract}

\section{INTRODUCTION}

Electrical accidents are commonly misclassified as either low or high voltage with an arbitrary cutoff usually set at $1000 \mathrm{~V}$. The voltage cutoff leads to some diagnostic errors. The 1,000,000-25,000,000 V Van de Graff generator does not cause injury as the power and current are almost zero. Nor does the $8 \mathrm{kV}$ static shock (30 A peak) outlined in the IEC (International Electrotechnical Commission) standard. ${ }^{1}$ A better classification is by power with a 1000 W cutoff.

The so-called "high-voltage" electrocutions include lightning and power line sources. A $7600 \mathrm{~V}$ power line can easily deliver about $60 \mathrm{~kW}$ of power to someone standing on the ground (or on an aluminum ladder) and touching the power line with a tool. Injuries can include arrhythmias, burns, superficial or deeper nerve damage, muscle damage with rhabdomyolysis and subsequent renal problems, and paralysis. Actual myocardial damage is often demonstrated. ${ }^{2-9}$

Such levels of systemic damage lead to numerous mechanisms of death and go beyond the scope of this review. Hence, this review will focus on low-power elec-

M.W. Kroll is with the Biomedical Engineering Dept. at the University of Minnesota, Minneapolis, MN. Member of TASER International, Inc. (TASER) corporate and scientific advisory board. Email: kroll051@umn.edu

R.M. Fish is with the Universty of Illinois, Chicago, IL. Email: rfish@uiuc.edu

D.J. Lakkireddy is with the University of Kansas Hospital, Kansas City, KS. Email: dlakkireddy@gmail.com

R. M. Luceri is with Holy Cross Hospital, Ft. Lauderdale, FL. Member TASER scientific advisory board Email:rluceri@yahoo.com

D. Panescu is with Intuitive Surgical, Sunnyvale, CA. Email: dorin.panescu@intusurg.com trocutions which cause death without causing systemic damage.

\section{ESTABLISHED MECHANISMS}

\section{Arrhythmia Induction}

The electrical injury of greatest concern is a lethal ventricular arrhythmia. The signature rhythm of electrocution is ventricular fibrillation (VF). It was long thought that there were only 2 means of inducing VF in the healthy heart with electrical currents. The first is the "shock on T" which involves delivering a single strong electrical pulse during the time of the T-wave to instantly cause VF. 10,11 The second method requires causing extremely rapid cardiac capture - typically $>450$ BPM (beats per minute) - which induces VF within a few seconds in a normal heart. ${ }^{12-14}$ This is classical "electrocution." This electrically-induced VF mechanism takes far less current than "T-shock" induction but also several pulses (typically at least 6 pulses. $)^{15}$ It has recently been recognized that there is a $3^{\text {rd }}$ method of inducing VF, namely with long-term high-rate cardiac capture causing sufficient ischemia to lower the VF threshold (VFT) to allow for the induction of VF. ${ }^{16}$ See Table 1 for a summary.

\section{Single Pulse into the T-wave}

The T-wave represents the time when the myocytes are returning back to their "resting" state. Some cells are absolute refractory while some are relatively refractory to electrical stimulation. Still others are depolarized and amenable to stimulation. A shock of appropriate charge during the T-wave leads instantly to VF from reentry. ${ }^{17}$ That is why the T-wave is referred to as the "vulnerable" portion of the heartbeat. For blunt trauma, mechanical energy delivered into the T-wave can also induce VF with a condition referred to as "commotio cordis." 18, 19

Dorian, et al reported that delivering electrical charge into the T-wave sufficient to induce VF took a mean of 19 $\mathrm{J}$ (joules) with external patches. ${ }^{20}$ One can calculate that this corresponds to an electrical charge of about 100,000 $\mu \mathrm{C}$ (microcoulombs) assuming typical external defibrillator capacitances. ${ }^{20}$ Swerdlow had a patient (unpublished) that he induced with only $1 \mathrm{~J}$ which (assuming typical capacitances) corresponds to about $20,000 \mu \mathrm{C}$ of delivered electrical charge. ${ }^{21}$ The value of $5,000 \mu \mathrm{C}$ is what the IEC considers to be at the $50 \%$ probability of VF risk with unidirectional impulse currents of short durations delivered into the T-wave. ${ }^{22}$ 


\section{Multiple Pulses And "Direct" VF Induction}

Sufficiently strong repetitive external currents delivered to the heart will capture epicardial cells. According to the "multiple wavelet" hypothesis of VF, formation of new wavelets occurs through the process of wave break (or wave splitting), in which a wavelet breaks into new (daughter) wavelets. ${ }^{23}$ Wave break occurs at sites of electrophysiological inhomogeneity, where regions of refractoriness provide opportunities for reentry to form. Epicardial cells are intrinsically heterogeneous in their repolarization properties. ${ }^{24}$ This intrinsic heterogeneity provides a substrate for reentry formation during rapid ( $450 \mathrm{BPM})$ capture. When a portion of the incoming wave front encounters refractory tissue while other portions continue to propagate, wave break occurs leading to VF.

The VFT is the amount of current required to induce VF in a particular subject with a particular electrode location. Reilly, in his text "Applied Bioelectricity" compiled all published studies on the effects of a pulse-train duration on the direct electrical induction of VF. ${ }^{25}$ The VFT went down, with increasing pulse-train durations, until the exposure duration reached 1-5 $\mathrm{s}$. This is reflected in recognized standards, as shown in Figure 1 taken from Reilly. ${ }^{26}$ In other words, if an electrical current does not fibrillate within about $5 \mathrm{~s}$ it will not fibrillate with longer durations, (except as shown below by the $3^{\text {rd }}$ mechanism of extended high-rate capture ischemically lowering the VFT).

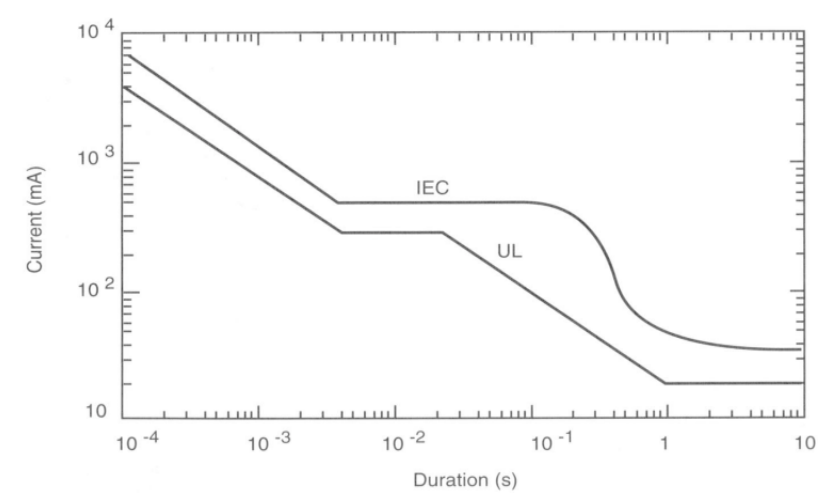

Figure 1. UL (Underwriters Laboratories) and IEC standards for VF risk suggest that VF is either induced or not in the first few seconds.

\section{Long-Exposure High-Rate Cardiac Capture Ischemi- cally Lowering VFT}

High-rate cardiac capture with current densities of about $40 \%$ of the VFT will cause hypotensive collapse and will lead to VF after 90 seconds. ${ }^{27}$ The current densities for this hypotensive response are above the threshold for continuous hypotensive capture. ${ }^{28,29}$ Continuous cardiac capture at rates of $>220 \mathrm{BPM}$, in swine, can eventually lead to VF. The required durations for this are on the order of minutes rather than seconds.

Prolonged rapid capture reduces cardiac output at the same time that the heart muscle continues to need blood. This causes ischemia sufficient to lower the VFT in about 90 seconds in swine. In large mammals, with ischemia the VFT is cut to about $40 \%$ (of the directinduction VFT).

The ability of rapid short pulses to induce VF is approximately equal to a $60 \mathrm{~Hz} \mathrm{AC}$ current with RMS current of 7.4 times the aggregate current of the rapid short pulses. ${ }^{30}$ For example the aggregate current of a nerve stimulator with $100 \mu \mathrm{C}$ pulses with a rate of 20 PPS is $2 \mathrm{~mA}$. This has the VF-inducing capability of an AC source of $14.8 \mathrm{~mA}$ RMS. Note: The US FDA refers to this aggregate current value (charge $\cdot$ pulse rate) as the "average" current. ${ }^{31}$

Table 1. Mechanism of electrocution for various shock durations.

\begin{tabular}{|l|l|l|}
\hline Duration & Mechanism & $\begin{array}{l}\text { Qualitative Current } \\
\text { Levels }\end{array}$ \\
\hline $1-10 \mathrm{~ms}$ & $\begin{array}{l}\text { Single Pulse Shock on } \\
\mathrm{T}\end{array}$ & $\begin{array}{l}\text { Requires very strong } \\
\text { current. }\end{array}$ \\
\hline $\begin{array}{l}\text { 1-5 } \mathrm{s} \\
\text { (train) }\end{array}$ & Direct induction of VF & $\begin{array}{l}\text { Possible with strong } \\
\text { electric current in any } \\
\text { part of a ventricle. }\end{array}$ \\
\hline $\begin{array}{l}5-80 \mathrm{~s}^{*} \\
\text { (train) }\end{array}$ & No known mechanism & $\begin{array}{l}\text { Unlikely with electrical } \\
\text { current unless current } \\
\text { is at the edge of the } \\
\text { VFT. }\end{array}$ \\
\hline $\begin{array}{l}90-300 \mathrm{~s} \\
\text { (train) }\end{array}$ & $\begin{array}{l}\text { High-rate cardiac cap- } \\
\text { ture leading to ische- } \\
\text { mia lowering VFT. }\end{array}$ & $\begin{array}{l}\text { Possible with weaker } \\
\text { current in any part of a } \\
\text { ventricle. }\end{array}$ \\
\hline
\end{tabular}

*There are some controversial data with $80 \mathrm{~s}$ exposures. However, this was in unventilated anesthetized swine. ${ }^{32,33}$

Figure 2 shows the 3 distinct time scales for the induction of VF by electrical current. The T-shock induction occurs instantly and is shown by the vertical line at 0 seconds. Direct (multiple pulse) induction of VF occurs typically in 0.1 - 5 seconds with the current required decreasing rapidly. Long-duration continuous high-rate capture (with current densities $\sim 40 \%$ of the VFT) leads to an ischemically reduced VFT after $\sim 90 \mathrm{~s}$, or longer. It is important to note - and clearly shown by Scott's canine data - that there is no known mechanism for $\mathrm{VF}$ induction taking $5-60$ s. ${ }^{34}$ The Nimunkar swine results required a median $150 \mathrm{~s}$ ( $300 \mathrm{~s}$ with $50 \%$ duty cycle of $5 \mathrm{~s}$ on and $5 \mathrm{~s}$ off) to induce VF with high-rate capture. ${ }^{35}$ Finally, Roy showed that a cardiac arrest would always occur within $300 \mathrm{~s}$ with hypotensive capture in canines. ${ }^{36}$ In swine current durations between 5 and 80 seconds are not shown to cause $\mathrm{VF} .{ }^{27}$

\section{SPECULATED MECHANISMS}

There are 4 speculated additional mechanisms for lowpower electrocution. These are: respiratory arrest, asystole from direct current, induction of an intermediate ventricular tachycardia (VT), and accommodation of the VERP (ventricular effective refractory period). 


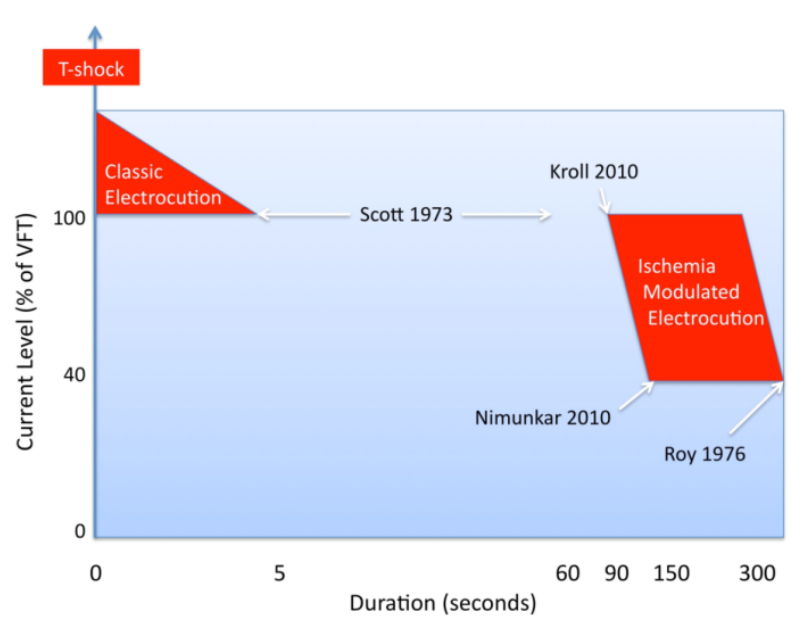

Figure 2. There are 3 distinct shock duration periods with which VF can be electrically induced.

\section{Respiratory Arrest}

Sufficient thoracic current can temporarily induce respiratory arrest. This current can be lower than the threshold for VF especially if it is conducted hand-to-hand as that can provide a pathway via the trapezius muscles capturing the phrenic nerves near the neck. There is even a case of respiratory compromise from a TENS (Transcutaneous Electronic Nerve Stimulator) delivering maximum current across the chest for angina pectoris. ${ }^{37}$ Lightning can certainly cause respiratory arrest by first causing permanent damage to the brain. ${ }^{8}$

However, the speculated mechanism of an electrically-induced respiratory arrest raises several questions. The most likely scenario would be someone grabbing an exposed source with the total pathway resistance limiting the current to a level between 20-50 mA AC. Note that this is a very narrow band of currents. The current must be greater than both the "let-go" levels and the minimum for respiratory arrest. ${ }^{38,39}$ However, it must be $<\sim 150$ $\mathrm{mA}$ (depending on the current pathway, and the subject's weight) or VF would be instantly induced. ${ }^{40}$ And, it must be less than $40 \%$ of the VFT or high-rate cardiac capture will lead to VF in 90 seconds which is sooner than a death from respiratory arrest. ${ }^{16} \mathrm{AC}$ currents of $50-80 \%$ of the VF threshold will also cause temporary cardiovascular collapse due to rapid regular excitation. ${ }^{28,41}$

Electrical bilateral stimulation of the forearm muscles will quickly cause fatigue as electrical muscle stimulation is very fatiguing, per se, and the bilateral stimulation is tiring. ${ }^{42-44}$ Thus, the subject would release the connection. No documented case of low-power electrocution via respiratory arrest has been identified. Therefore it is most likely that persons with apparent respiratory arrest due to transthoracic current flow will die from VF rather than from asphyxia itself.

\section{Asystole from Direct Current}

It is a common misunderstanding in the medical fields that AC causes VF but that DC (or a battery) causes asystole. This is reinforced by the US Medical Licensing Examination which sometimes has a question related to the myth that batteries can cause asystole. ${ }^{45}$ This is, of course false as batteries can be touched directly to the epicardium and will only produce VF. ${ }^{17,}{ }^{46}$ It is hard to pinpoint the source of this myth. Portable external now-obsolete monophasic defibrillators would sometimes cause postshock asystole. (Modern biphasic defibrillators can also cause post-shock PEA and asystole.) They were classically referred to as "DC" defibrillators to differentiate them from the utility-powered AC defibrillators. Also, lighting can certainly cause asystole through nerve or cardiac nodal damage and lightning is, indeed, a DC shock. ${ }^{47,48}$

\section{VT and Delayed Cardiac Arrest}

A speculation - that has been raised to attempt to argue for a long gap between an electrical exposure and VF is that the electrical current induced an intermediate VT. Important definitions:

1. Sustained VT: a VT that lasts for more than 30 seconds.

2. Unstable VT: a VT that causes symptoms - most commonly passing out (syncope). Note that the "unstable" refers to the blood pressure being unstable not the VT.

The intermediate VT induction speculation is scientifically unsupportable for several reasons:

1. A sustained VT cannot be induced in the absence of a myocardial reentrant substrate like nonhomogenous scar caused by a prior myocardial insult (myocardial infarction, myocarditis, etc.). ${ }^{49-52}$ By definition, only a sustained VT would possibly allow a delay to cardiac arrest of more than 30 seconds. A small exception is HCM (hypertrophic cardiomyopathy). In some HCM patients a sustained VT can be induced with specialized pulse sequences but this is not expected. ${ }^{49}$ In a swine study, a VT was induced in a normal heart (probably by a large infusion of epinephrine) but it only persisted for 7 seconds. ${ }^{53}$ Meanwhile the blood pressure was $40 \mathrm{~mm}$ suggestive of the unstable nature of the rhythm with ensuing hemodynamic compromise. (The subject would have lost consciousness had it not been already anesthetized).

2. A VT that will lead to VF is almost always an "unstable" VT. An unstable VT will degenerate into VF within $34 \pm 7$ seconds in humans. ${ }^{54}$ Hence, a VF delayed by, say, 60 seconds is extremely unlikely.

3. Any VT that leads to VF has such a rapid heart rate that it almost always leads to immediate syncope (loss of consciousness). ${ }^{54,55}$

4. VT induction generally requires specialized pulse timings and is generally not inducible with steady rate currents such as those from utility power, DC, or 
an ECD. ${ }^{52,}{ }^{56}$ Using specialized pulse timings, Cua was able to induce monomorphic VT in patients with a history of VT; however, steady AC stimulation universally induced only VF. ${ }^{57}$

5. VT has never been documented in the literature as a cardiac rhythm in ARDs (arrest-related deaths) where an electronic control device (ECD) was temporally used. $^{58,59}$ In many cases of deaths considered temporal with ECD usage, the suspect was being cardiac monitored before any arrhythmias developed. And in these incidents VT was also not seen.

6. There are rare cases of VT following electrical injury, but none progressed to a cardiac arrest. Haim reported a VT in a 17 yo male electrocution who was hypotensive yet conscious. ${ }^{60}$ Jensen reported a 45 yo woman that had VT after an alleged exposure to 430 VAC. ${ }^{61}$ This case is suspicious as she did not present until 60 days after the alleged exposure. Neither of these cases led to VF or any type of cardiac arrest and hence are not directly relevant.

There are some very uncommon VTs that do not require a diseased heart. These include:

1. Idiopathic normal heart VTs (originating in the RV and LV outflow tracts, His Purkinje system, aortic cusps, and sub valvular regions)

2. Catecholaminergic Polymorphic VT (CPVT)

3. Torsades de Pointes (TdP) is a polymorphic VT spontaneously induced by metabolic (low K, low $\mathrm{Ca}$ or low $\mathrm{Mg}$ ) or drug (dofetalide, sotalol, some psychotropics, and methadone) related effects.

These are not relevant as they are either nonsustained, difficult to electrically induce, not associated with cardiac arrest, or very symptomatic and associated with syncope. ${ }^{56} 6263$

Several literature reviews have cast doubt on the possibility of a delayed cardiac arrest from low power electrical stimulation. ${ }^{64-66}$

There is a controversial example of a swine with an electrically-induced VT lasting 3 minutes which appears - at first blush - to contradict the human data that a sustained VT generally requires an infarct scar. ${ }^{33}$

1. The pig had received 80 seconds of high-rate cardiac capture which would cause severe myocardial ischemia. In addition, the anesthetized pig was not allowed to breath during the 80-second ECD application (40 s on, $10 \mathrm{~s}$ break, and then $40 \mathrm{~s}$ on), which would have exacerbated the ischemic acidosis. This pig may have started out with a normal heart but it was far from normal when this VT was documented.

2. Not only was this seen in only 1 of the 6 swine tested, a sustained VT has never been documented in numerous swine studies where the animals were allowed to breath. ${ }^{27,53,67-71}$

3. The high rate of the VT would have resulted in a loss of pulse and consciousness and thus is not applicable to the typical human ARD case where delayed VF is speculated.

\section{VERP Accommodation}

The Ventricular Effective Refractory Period (VERP) accommodation theory suggests a new mechanism for electrical stimulation inducing VF in, say, 37 seconds after failing to do so in the initial 5 seconds. This contradicts all published literature which shows that an electrical current insufficient to induce VF, in a normal heart, in 5seconds cannot do so until 90 seconds of exposure. ${ }^{12-14,26 \text {, }}$ 28, 34, 36, 72-76 This VERP theory is based on the idea that the high-rate continuous capture would cause the VERP to gradually shorten and this would lead to VF.

The VERP is the heart's own "governor" that safely limits the rate at which the heart can beat. For a healthy human at rest, the VERP normally ranges around 200-250 ms, even though the heart may be beating at a much slower rate. This means that, with a VERP of 250 $\mathrm{ms}$, the maximum heart rate, with continuous electrical stimulation below the VFT, is about 4 times a second or 240 BPM. Catecholamine (adrenaline) release in the body from agitation and stress might also shorten the VERP. However, the theory is that increased heart rate, along with the catecholamine increase caused by the agitation shortens the VERP to something like $200 \mathrm{~ms}$, allowing the capture rate to increase to 300 BPM. That new rate further shortens the VERP, which increases the heart rate still further, perhaps triggering irregular captures (the capture ratio does not necessarily remain constant) that adds to the disorganization of the heart beat, until a rate of 450 BPM results which produces VF.

The VERP theory suggests that over a century of published research on VF induction and electrical safety standards is wrong.

The argument behind the VERP theory appears to be that intermittent stimulation changes everything. E.g. the movement of the chest wall changes the spacing between a chest contact and the heart and thus cardiac capture is irregular. There are 3 major problems with this VERP theory speculation:

1. Electrical safety studies used ventilated animals so their chests were being inflated regularly by the ventilator. None of these researchers reported intermittent capture even though the heart's thoracic position was changing.

2. The animal VF safety studies would slowly increase the AC current until VF was finally induced. For example, Scott used steady currents for 60 seconds at each current level. ${ }^{34}$ As he would get close to the VF threshold, he would have certainly had some intermittent capture. This never led to any surprisingly low VF inductions being reported.

3. Human endocardial pacing studies show that even $20 \mu \mathrm{C}$ pulses - subthreshold since delivered during the refractory period - extend rather than shorten the VERP. ${ }^{77}$ This directly contradicts any speculation 
- that intermittent capture from a rapid source would facilitate VERP accommodation - as the noncapturing pulses would be subthreshold during the refractory period and would extend it.

The VERP accommodation theory apparently rests on an animal study. ${ }^{78}$ Unfortunately, for this VERP theory, human studies are not suportive. The Zipes group paced human ventricles at $150 \mathrm{BPM}$ for 30 minutes. ${ }^{79}$ They concluded (abstract), "In contrast to traditional concepts of refractoriness, after the termination of sustained rapid ventricular rates, VERP prolonged."

Even if the VERP does shorten, it does not adjust fast enough or far enough. Morady et al published a human study of 23 patients. ${ }^{80}$ The study found that the VERP adjustment took $93 \pm 34$ seconds $(233 \pm 85$ beats $)$ of continuous rapid cardiac capture (150 BPM) to get to a $200 \mathrm{~ms}$ VERP. And none of the patients ever had VF. The same study also looked at the effects of catecholamine in 6 of the patients. They found that the minimum VERP was $202 \pm 7 \mathrm{~ms}$ vs. $206 \pm 12 \mathrm{~ms}$ (NS) with and without catecholamine influence.

Finally, the Morady study maintained the rapid cardiac capture for 10 minutes ( $\mathrm{n}=12$ patients) and the VERP never decreased below $200 \mathrm{~ms}$. And, VF was never seen. Thus the scientifically unsupported speculation that this VERP theory mechanism would eventually lead to $\mathrm{VF}$ is unfounded and contrary to the published human literature.

The Morady study, used 100 and 150 BPM pacing and then used Methods " $A$ " and " $B$ " to determine the VERP. Only the 150 BPM Method B represents relevant human data since it alone achieved a $200 \mathrm{~ms}$ VERP as required for the VERP theory. For the relevant 150 BPM Method B results the fastest responding patient achieved his lowest VERP after 76 beats or 30 seconds. This was the extreme case and VF was still not induced.

Also, none of the recent published animal or human data shows any increase in the capture rate with time from rapid stimulation at 1120 BPM. Figure 2 of Nanthakumar shows a steady rate of capture over a 15second ECD application. ${ }^{53}$ The Cao pacemaker capture case shows steady capture measured at 281-290 ms cycle length. ${ }^{81}$ The Ho human capture case showed a steady capture rate of $240 \mathrm{BPM}(\mathrm{CL}=250 \mathrm{~ms}){ }^{82}$ Lakkireddy never saw the capture rate increase during hs multiple animal tests. $^{70,71}$

\section{CONCLUSIONS}

There are the 3 established mechanisms for low-power electrocution: (1) shock on cardiac T-wave, (2) direct induction of VF, and (3) induction of VF from long-term high-rate cardiac capture ischemically lowing the VFT. We examined 4 other proposed mechanisms: (1) respiratory arrest, (2) asystole from direct current, (3) induction of an intermediate ventricular tachycardia, and (4) ac- commodation of the VERP (ventricular effective refractory period). None of the speculated mechanisms are scientifically supportable.

\section{REFERENCES}

1. International Electrotechnical Commission. Electromagnetic compatibility (EMC) - Part 4-2: Testing and measurement techniques - Electrostatic discharge immunity test. Vol IEC 61000-4-2: IEC.

2. Kondur AK, Afonso LC, Berenbom LD, Lakkireddy DR. Implantable cardioverter defibrillators save lives from lightning-related electrocution too! Pacing Clin Electrophysiol. Feb 2008;31(2):256-257.

3. Donoghue E, Lifschultz B. Electrical and Lightning Injuries. In: Spitz W, ed. Medicolegal Investigation of Death. 4 ed. Springfield, IL: Charles C. Thomas; 2006:882-901.

4. Lee RC, Zhang D, Hannig J. Biophysical injury mechanisms in electrical shock trauma. Annu Rev Biomed Eng. 2000;2:477-509.

5. Jain S, Bandi V. Electrical and lightning injuries. Crit Care Clin. Apr 1999;15(2):319-331.

6. Cooper MA. Emergent care of lightning and electrical injuries. Semin Neurol. Sep 1995;15(3):268-278.

7. Lichtenberg R, Dries D, Ward K, Marshall W, Scanlon P. Cardiovascular effects of lightning strikes. $J$ Am Coll Cardiol. Feb 1993;21(2):531-536.

8. Fontanarosa PB. Electrical shock and lightning strike. Ann Emerg Med. Feb 1993;22(2 Pt 2):378-387.

9. Ekoe JM, Cunningham M, Jaques $\mathrm{O}$, et al. Disseminated intravascular coagulation and acute myocardial necrosis caused by lightning. Intensive Care Med. 1985;11(3):160162.

10. Swerdlow C, Martin D, Kass R, et al. The zone of vulnerability to T-wave shocks in humans. $J$ Cardiovasc Electrophysiol. 1997;8:145-154.

11. Wiggers CJ, Wegria R. Ventricular fibrillation due to single, localized induction and condenser shocks applied during the vulnerable phase of ventricular systole. Am J Physiol J1 AJP. 1940;128:500-505.

12. Antoni $H$. Pathophysiological basis of ventricular fibrillation. In: Bridges JF, Ford GL, Sherman IA, Vainberg M, eds. Electrical Shock Safety Criteria. New York: Pergammon Press; 1985:33-43.

13. Ferris LP, King BG, Spence PW, Williams HB. Effect of electric shock on the heart. Electrical Engineering. 1936;55:498-515.

14. Jacobsen J, Buntenkotter S, Reinhard HJ. [Experimental studies in pigs on mortality due to sinusoidal and phasecontrolled alternating and rectified currents (author's transl)]. Biomed Tech (Berl). Jun 1975;20(3):99-107.

15. Sugimoto, Schaal, Wallace. Factors determining vulnerability to ventricular fibrillation induced by $60-\mathrm{cps}$ alternating current. Circ Res. 1967;21:601-608.

16. Kroll MW, Panescu D, Hinz AF, Lakkireddy D. A novel mechanism for electrical currents inducing ventricular fibrillation: The three-fold way to fibrillation. Conf Proc IEEE Eng Med Biol Soc. 2010;1:1990-1996.

17. Sharma AD, Fain E, O'Neill PG, et al. Shock on T versus direct current voltage for induction of ventricular fibrillation: 
a randomized prospective comparison. Pacing Clin Electrophysiol. Jan 2004;27(1):89-94.

18. Geddes LA, Roeder RA. Evolution of our knowledge of sudden death due to commotio cordis. Am J Emerg Med. Jan 2005;23(1):67-75.

19. Link MS, Estes NA, 3rd. Mechanically induced ventricular fibrillation (commotio cordis). Heart Rhythm. Apr 2007;4(4):529-532.

20. Mazer CD, Greene MB, Misale PS, Newman D, Dorian P. Transcutaneous $\mathrm{T}$ wave shock: a universal method for ventricular fibrillation induction. Pacing Clin Electrophysiol. Dec 1997;20(12 Pt 1):2930-2935.

21. Swerdlow C. Induction of ventricular fibrillation with a 1joule transthoracic shock. In: Kroll M, ed2008.

22. International Electrotechnical Commission. Effects of Current on Human Beings and Livestock, CEI/IEC 479-2: Effects of currents passing through the human body, 2nd Edition. IEC 60479-2. 2nd ed: IEC, Geneva, Switzerland; 1987.

23. Nash MP, Mourad A, Clayton RH, et al. Evidence for multiple mechanisms in human ventricular fibrillation. Circulation. Aug 8 2006;114(6):536-542.

24. Voroshilovsky $\mathrm{O}, \mathrm{Qu} \mathrm{Z}$, Lee $\mathrm{MH}$, et al. Mechanisms of ventricular fibrillation induction by $60-\mathrm{Hz}$ alternating current in isolated swine right ventricle. Circulation. Sep 26 2000;102(13):1569-1574.

25. Reilly JP. Applied Bioelectricity: From Electrical Stimulation to Electrical Pathology. New York: Springer; 1998.

26. Chilbert M. Standards and Rationale. In: Reilly J, ed. Applied Bioelectricity: From Electrical Stimulation to Electrical Pathology. New York: Springer; 1998:454-501.

27. Kroll M, Panescu D, Hinz A, Lakkireddy D. A Novel Mechanism for Electrical Currents Inducing Ventricular Fibrillation: The Three-Fold Way to Fibrillation Engineering in Medicine and Biology Society Proceedings. Sept 2010:1990-1996.

28. Swerdlow CD, Olson WH, O'Connor ME, Gallik DM, Malkin RA, Laks M. Cardiovascular collapse caused by electrocardiographically silent $60-\mathrm{Hz}$ intracardiac leakage current. Implications for electrical safety. Circulation. May 18 1999;99(19):2559-2564.

29. Hohnloser SH, Verrier RL, Lown B, Raeder EA. Effect of hypokalemia on susceptibility to ventricular fibrillation in the normal and ischemic canine heart. Am Heart J. Jul 1986;112(1):32-35.

30. Walcott G, Kroll M, Ideker R. Ventricular Fibrillation Threshold of Rapid Short Pulses. Conf Proc IEEE Eng Med Biol Soc. 2011:255-258.

31. Cunningham B. Draft Guidance for Industry and FDA Staff: Class II Special Controls Guidance Document: Transcutaneous Electrical Nerve Stimulator with Limited Output for Pain Relief. 2011; http://www.fda.gov/MedicalDevices/DeviceRegulationandG uidance/GuidanceDocuments/ucm198585.htm, 2012.

32. Walter RJ, Dennis AJ, Valentino DJ, et al. TASER X26 discharges in swine produce potentially fatal ventricular arrhythmias. Acad Emerg Med. Jan 2008;15(1):66-73.

33. Dennis AJ, Valentino DJ, Walter RJ, et al. Acute effects of TASER X26 discharges in a swine model. J Trauma. Sep 2007;63(3):581-590.

34. Scott JR, Lee WR, Zoledziowski S. Ventricular fibrillation threshold for AC shocks of long duration, in dogs with normal acid-base state. $B r J$ Ind Med. Apr 1973;30(2):155161.

35. Nimunkar A, Wu J, O'Rourke A, Huebner S, Will J, Webster J. Ventricular fibrillation and blood chemistry after multiple Tasering of Pigs. Physiol Meas. 2010

36. Roy OZ, Park GC, Scott JR. Intracardiac catheter fibrillation thresholds as a function of the duration of $60 \mathrm{~Hz}$ current and electrode area. IEEE Transactions on Biomedical Engineering. 1977;BME-24(5):430-435.

37. Mann CJ. Respiratory compromise: a rare complication of transcutaneous electrical nerve stimulation for angina pectoris. J Accid Emerg Med. Jan 1996;13(1):68.

38. Sweeney JD. A theoretical analysis of the "let-go" phenomenon. IEEE Trans Biomed Eng. Dec 1993;40(12):1335-1338.

39. Fish R. Electric shock, Part II: Nature and mechanisms of injury. J Emerg Med. Jul-Aug 1993;11(4):457-462.

40. Dalziel CF, Lee WR. Reevaluation of lethal electric currents. IEEE Transactions on Industry and General Applications. 1968;IGA-4(5):467-476.

41. Malkin RA, Hoffmeister BK. Mechanisms by which AC leakage currents cause complete hemodynamic collapse without inducing fibrillation. J Cardiovasc Electrophysiol. Oct 2001;12(10):1154-1161.

42. Gregory CM, Dixon W, Bickel CS. Impact of varying pulse frequency and duration on muscle torque production and fatigue. Muscle Nerve. Apr 2007;35(4):504-509.

43. Ding J, Wexler AS, Binder-Macleod SA. A predictive fatigue model--I: Predicting the effect of stimulation frequency and pattern on fatigue. IEEE Trans Neural Syst Rehabil Eng. Mar 2002;10(1):48-58.

44. Peckham PH, Mortimer JT, Marsolais EB. Alteration in the force and fatigability of skeletal muscle in quadriplegic humans following exercise induced by chronic electrical stimulation. Clin Orthop Relat Res. Jan-Feb 1976(114):326333.

45. Le T, Bhushan V, Bagga H. First Aid for the USMLE Step 3. 3rd ed. New York: McGraw Hill Medical; 2011.

46. Euler DE, Whitman TA, Roberts PR, Kallok MJ. Low voltage direct current delivered through unipolar transvenous leads: an alternate method for the induction of ventricular fibrillation. Pacing Clin Electrophysiol. Jun 1999;22(6 Pt 1):908-914.

47. Guinard JP, Chiolero R, Buchser E, et al. Myocardial injury after electrical burns: short and long term study. Scand J Plast Reconstr Surg Hand Surg. 1987;21(3):301-302.

48. James TN, Riddick L, Embry JH. Cardiac abnormalities demonstrated postmortem in four cases of accidental electrocution and their potential significance relative to nonfatal electrical injuries of the heart. Am Heart J. Jul 1990;120(1):143-157.

49. Brugada $\mathrm{P}$, Abdollah H, Heddle B, Wellens HJ. Results of a ventricular stimulation protocol using a maximum of 4 premature stimuli in patients without documented or suspected ventricular arrhythmias. Am J Cardiol. Dec 1 1983;52(10):1214-1218.

50. Brugada $P$, Green $M$, Abdollah $H$, Wellens HJ. Significance of ventricular arrhythmias initiated by programmed ventricular stimulation: the importance of the type of ventricular arrhythmia induced and the number of premature stimuli required. Circulation. Jan 1984;69(1):87-92.

51. Morady F, Shapiro W, Shen E, Sung RJ, Scheinman MM. Programmed ventricular stimulation in patients without 
spontaneous ventricular tachycardia. Am Heart J. May 1984;107(5 Pt 1):875-882.

52. Brugada P. Programmed electrical stimulation of the human heart. In: Josephson, ed. Tachycardia-mechanisms, diagnosis, treatment. Philadelphia: Lea \& Febiger; 1984:6189.

53. Nanthakumar K, Billingsley IM, Masse S, et al. Cardiac electrophysiological consequences of neuromuscular incapacitating device discharges. $J$ Am Coll Cardiol. Aug 15 2006;48(4):798-804.

54. Huikuri HV, Zaman L, Castellanos A, et al. Changes in spontaneous sinus node rate as an estimate of cardiac autonomic tone during stable and unstable ventricular tachycardia. J Am Coll Cardiol. Mar 1 1989;13(3):646-652.

55. Stevenson WG, Brugada $P$, Waldecker $B$, Zehender $M$, Wellens HJ. Clinical, angiographic, and electrophysiologic findings in patients with aborted sudden death as compared with patients with sustained ventricular tachycardia after myocardial infarction. Circulation. Jun 1985;71(6):11461152.

56. Lerman BB, Stein K, Engelstein ED, et al. Mechanism of repetitive monomorphic ventricular tachycardia. Circulation. Aug 1 1995;92(3):421-429.

57. Cua M, Veltri EP. A comparison of ventricular arrhythmias induced with programmed stimulation versus alternating current. Pacing Clin Electrophysiol. 1993;16(3 Pt 1):382386.

58. Stratton SJ, Rogers C, Brickett K, Gruzinski G. Factors associated with sudden death of individuals requiring restraint for excited delirium. Am $J$ Emerg Med. May 2001;19(3):187-191.

59. Swerdlow CD, Fishbein MC, Chaman L, Lakkireddy DR, Tchou P. Presenting rhythm in sudden deaths temporally proximate to discharge of TASER conducted electrical weapons. Acad Emerg Med. Aug 2009;16(8):726-739.

60. Haim A, Zucker N, Levitas A, Sofer S, Katz A, Zalzstein E. Cardiac manifestations following electrocution in children. Cardiol Young. Oct 2008;18(5):458-460.

61. Jensen PJ, Thomsen PE, Bagger JP, Norgaard A, Baandrup U. Electrical injury causing ventricular arrhythmias. $\mathrm{Br}$ Heart J. Mar 1987;57(3):279-283.

62. Buxton AE, Marchlinski FE, Doherty JU, et al. Repetitive, monomorphic ventricular tachycardia: clinical and electrophysiologic characteristics in patients with and patients without organic heart disease. Am J Cardiol. Nov 1 1984;54(8):997-1002.

63. Zipes DP, Jalife J. Cardiac Electrophysiology: From Cell to Bedside. Philadelphia: Saunders; 1990.

64. Vilke GM, Bozeman WP, Chan TC. Emergency Department Evaluation after Conducted Energy Weapon Use: Review of the Literature for the Clinician. J Emerg Med. Jan 82011.

65. Pasquier M, Carron PN, Vallotton L, Yersin B. Electronic control device exposure: a review of morbidity and mortality. Ann Emerg Med. Aug 2011;58(2):178-188.

66. Ideker RE, Dosdall DJ. Can the direct cardiac effects of the electric pulses generated by the TASER X26 cause immediate or delayed sudden cardiac arrest in normal adults? Am J Forensic Med Pathol. Sep 2007;28(3):195-201.

67. Kroll MW, Panescu D, Carver M, Kroll RM, Hinz AF. Cardiac effects of varying pulse charge and polarity of
TASER(R) conducted electrical weapons. Conf Proc IEEE Eng Med Biol Soc. 2009;1:3195-3198.

68. Valentino DJ, Walter RJ, Dennis AJ, et al. Taser X26 discharges in swine: ventricular rhythm capture is dependent on discharge vector. J Trauma. Dec 2008;65(6):1478-1485; discussion 1485-1477.

69. McDaniel WC, Stratbucker RA, Nerheim M, Brewer JE. Cardiac safety of neuromuscular incapacitating defensive devices. Pacing Clin Electrophysiol. Jan 2005;28 Suppl 1:S284-287.

70. Lakkireddy D, Wallick D, Ryschon K, et al. Effects of cocaine intoxication on the threshold for stun gun induction of ventricular fibrillation. $J \mathrm{Am}$ Coll Cardiol. Aug 15 2006;48(4):805-811.

71. Lakkireddy D, Wallick D, Verma A, et al. Cardiac effects of electrical stun guns: does position of barbs contact make a difference? Pacing Clin Electrophysiol. Apr 2008;31(4):398408.

72. Schipke JD, Heusch G, Sanii AP, Gams E, Winter J. Static filling pressure in patients during induced ventricular fibrillation. Am $J$ Physiol Heart Circ Physiol. Dec 2003;285(6):H2510-2515.

73. Wegria R, Wiggers CJ. Production of ventricular fibrillation by alternating currents. Am J Physiol. 1940;131:119.

74. Biegelmeier. Effect of current passing through the human body and the electrical impedance of the human body: A guide to IEC-Report 469. VDE,-Verlag, Berlin: ETZ;1987. 20.

75. Biegelmeier G, Lee WR. New considerations on the threshold of ventricular fibrillation for a.c.shocks at 50 60 Hz. IEE Proc. 1980;127(2):Pt. A: 103-110.

76. Kiselev A. Threshold values of safe current at mains frequency. Problems of electrical equipment, electrical supply and electrical measurements (in Russian). Sborllik MIIT. 1963;171:47-58

77. Windle JR, Miles WM, Zipes DP, Prystowsky EN. Subthreshold conditioning stimuli prolong human ventricular refractoriness. Am $J$ Cardiol. Feb 15 1986;57(6):381-386.

78. Janse MJ, van der Steen AB, van Dam RT. Refractory period of the dog's ventricular myocardium following sudden changes in frequency. Circ Res. Feb 1969;24(2):251262.

79. Krebs ME, Szwed JM, Shinn T, Miles WM, Zipes DP. Short-term rapid ventricular pacing prolongs ventricular refractoriness in patients. $J$ Cardiovasc Electrophysiol. Oct 1998;9(10):1036-1042.

80. Morady F, Kadish AH, Toivonen LK, Kushner JA, Schmaltz $\mathrm{S}$. The maximum effect of an increase in rate on human ventricular refractoriness. Pacing Clin Electrophysiol. Dec 1988;11(12):2223-2234.

81. Cao M, Shinbane JS, Gillberg JM, Saxon LA, Swerdlow CD. Taser-induced rapid ventricular myocardial capture demonstrated by pacemaker intracardiac electrograms. $J$ Cardiovasc Electrophysiol. Aug 2007;18(8):876-879.

82. Ho JD, Dawes DM, Reardon RF, et al. Human cardiovascular effects of a new generation conducted electrical weapon. Forensic Sci Int. Jan 30 2011;204(13):50-57. 